Revue bibliographique pour le domaine irano-aryen

\title{
Niccolò Manassero. “On some marks engraved on seals from Veh-Ardashir (Coche-Iraq)"
}

\section{Rémy Boucharlat}

\section{(2) OpenEdition}

12 Journals

\section{Édition électronique}

URL : http://journals.openedition.org/abstractairanica/51272

DOI : 10.4000/abstractairanica.51272

ISBN : 1961-960X

ISSN : 1961-960X

Éditeur :

CNRS (UMR 7528 Mondes iraniens et indiens), Éditions de l'IFRI

Référence électronique

Rémy Boucharlat, « Niccolò Manassero. "On some marks engraved on seals from Veh-Ardashir (Coche-Iraq)" », Abstracta Iranica [En ligne], Volume 40-41 | 2019, document 73, mis en ligne le 30 décembre 2019, consulté le 23 avril 2021. URL : http://journals.openedition.org/abstractairanica/ 51272 ; DOI : https://doi.org/10.4000/abstractairanica.51272

Ce document a été généré automatiquement le 23 avril 2021.

Tous droits réservés 


\title{
Niccolò Manassero. “On some marks engraved on seals from Veh- Ardashir (Coche-Iraq)"
}

\author{
Rémy Boucharlat
}

\section{RÉFÉRENCE}

Niccolò Manassero. "On some marks engraved on seals from Veh-Ardashir (CocheIraq)" in Paolo de Vingo (ed.). Le Archeologie di Marilli. Miscellanea di studi in ricordo di Maria Maddalena Negro Ponzi Mancini. Alessandria: Edizioni dell'Orso, 2018, (« Mnème », Documenti, culture, storia del Mediterraneo e dell'Oriente Antico, 12), p. 85-104

1 L'A. étudie une petite collection de six sceaux circulaires ou ovales ou quadrangulaires, trouvés dans les fouilles italiennes de Choche, la ville ronde de Ctésiphon, fondée au IIIe s. de n. è. L'un porte une série de triangles, un deuxième une sorte de croix, les quatre autres un véritable tamga, ou peut-être un végétal stylisé pour deux d'entre eux. Les motifs, en particulier le tamga, ne sont pas propres à l'art sassanide, ni particuliers au monde iranien. Seul le contexte archéologique pourrait aider à leur interprétation.

\section{AUTEURS}

RÉMY BOUCHARLAT

UMR 5133 CNRS-Université de Lyon 